\title{
Biomass energy in Bangladesh: current status and prospects
}

\begin{abstract}
Bangladesh has been experiencing several problems over the past few decades. These include over population, energy crisis and global warming, etc. Adequate amount of power generation in a sustainable way is an important issue for rapidly increasing population and economic development. Renewable energy can play an effective role to meet energy demand. Since it is an agrarian country, biomass is one of the potential renewable energy sources in Bangladesh. Agricultural crop residues, animal manure and municipal solid waste are the major sources of biomass energy in the country. This paper presents the scope, potential and technologies related to the use of biomass resources. The study also discusses the biomass projects undertaken by the government and non-government organizations, plans and strategies to promote biomass technologies in Bangladesh.
\end{abstract}

Keyword: Bangladesh; Biomass sources; Renewable; Alternative energy 